\title{
Characteristic of business environment of road construction in Russia
}

\author{
Marina Mishlanova ${ }^{1, *}$ and Gregory Syzrantsev ${ }^{1}$ \\ ${ }^{1}$ Moscow State University of Civil Engineering, Yaroslavskoe shosse, 26, Moscow, 129337, Russia
}

\begin{abstract}
The article notes the importance of the subsystem of road construction in the national economy. The insufficiency of methodological support for assessing the environment of economic activity is indicated. Statistical data on the state of the Russian road network are presented, disproportions of its development are revealed and problems of road construction are diagnosed. The article provides an assessment and comparative analysis of the life cycle of road construction enterprises. The complex of indicators of assessment of the environment of activity of the enterprises of road construction is offered, results of calculation of density and renewability of the environment for a row of years are considered. The level of state regulation of investment and construction activities in relation to the transport system is discussed. The negative factors and directions of improving the environment of road construction enterprises in Russia are highlighted.
\end{abstract}

\section{Introduction}

The effective functioning of the road network is a prerequisite for the development, integrity and national security of the country. The development of the road network affects the degree of urbanization, demographic index, the level of production and technical development of the territory [1, 2, 3, etc.]. Construction and operation of the road network are subsystems of the national economy, the subjects of which operate in a certain socioeconomic environment. Independent studies of a variety of socio-economic environments are not sufficiently developed, statistical technologies are not provided or are provided fragmentally [2, 4-10]. The purpose of these studies is to identify significant indicators of the environment of road construction enterprises and proposals for their assessment. The main research methods are the following: systematic approach, collection and processing of statistical data, retrospective analysis, time series analysis, identification of specific indicators of the environment and their transfer to the coefficient form.

\section{Empirical part}

The socio-economic development of Russia is constrained by the limitations of the road network: insufficient capacity, high degree of road wear, lag in the development of highways

\footnotetext{
*Corresponding author: mishlanova_m@mail.ru
} 
as part of international transport corridors, insufficient development of the road network in Siberia and the Far East.

In Russia, about $40 \%$ of public roads do not meet the regulatory requirements for transport and operational indicators. $56 \%$ of federal roads have unsatisfactory durability of pavement, $37 \%$ - unsatisfactory evenness of road surfaces, $36 \%$ - unsatisfactory coupling properties of road surfaces [11].

Analysis of the state of the Russian road network and road construction allows us to identify the problem area in the form of a significant system unevenness. $31 \%$ of the total number of rural settlements of the Russian Federation with a total population of 2.6 million people have no connection with the transport network of the country on public roads with hard surface [12].

In the regions of the North, Siberia and the Far East, the formation of the backbone road network has not been completed. In the Far North and equated territories, which occupy about $60 \%$ of the territory of the Russian Federation, there are less than $15 \%$ of roads, the density of paved roads is 15 times lower than in the whole of Russia $[3,12,13]$.

The territorial and spatial imbalance is complemented by imbalances of a different nature - between the accelerated growth of motorization of the population, the volume of road transport and the length of the national road network.

Road infrastructure lags behind rates of change of GDP, the number of vehicles, the demand for transportation.

The annual amount of losses associated with insufficient development of the road network and its low technical condition exceeds 3\% of Russia's GDP. The irrational development of the road network does not allow to fully master the territorial, natural resources and fuel and energy potential of Russia, to reduce transportation costs and to increase the competitiveness of road routes of the network of domestic and international roads.

The Russian road sector requires significant investment, but has low investment attractiveness. The applied procedure for financing the Russian transport sector is ineffective. The modern system of state regulation of the road sector is designed for a short period (3 years), the system of placement and budget financing of road works is ineffective.

The situation is compounded by inadequate regulations, questionable safeguards and a lack of systemic control. Diagnosis and generalization of problems at the micro level in relation to the subjects reveals the following problem areas: imperfection of tender, lack of real competition, late payment of works, a large debt of road workers, low reliability of equipment, etc.

\section{Results}

Analysis of statistical data [14] leads to the following conclusions. The current state of the investment and construction sector is characterized by a downward trend in the average length of stay of construction companies in the S\&P 500 index. Currently, about $66 \%$ of russian construction companies have a life cycle of less than 15 years, the average age of the subjects of this type of activity is 15.96 years, which is lower than the average of the country's economy by 1.08 years (Fig. 1). 


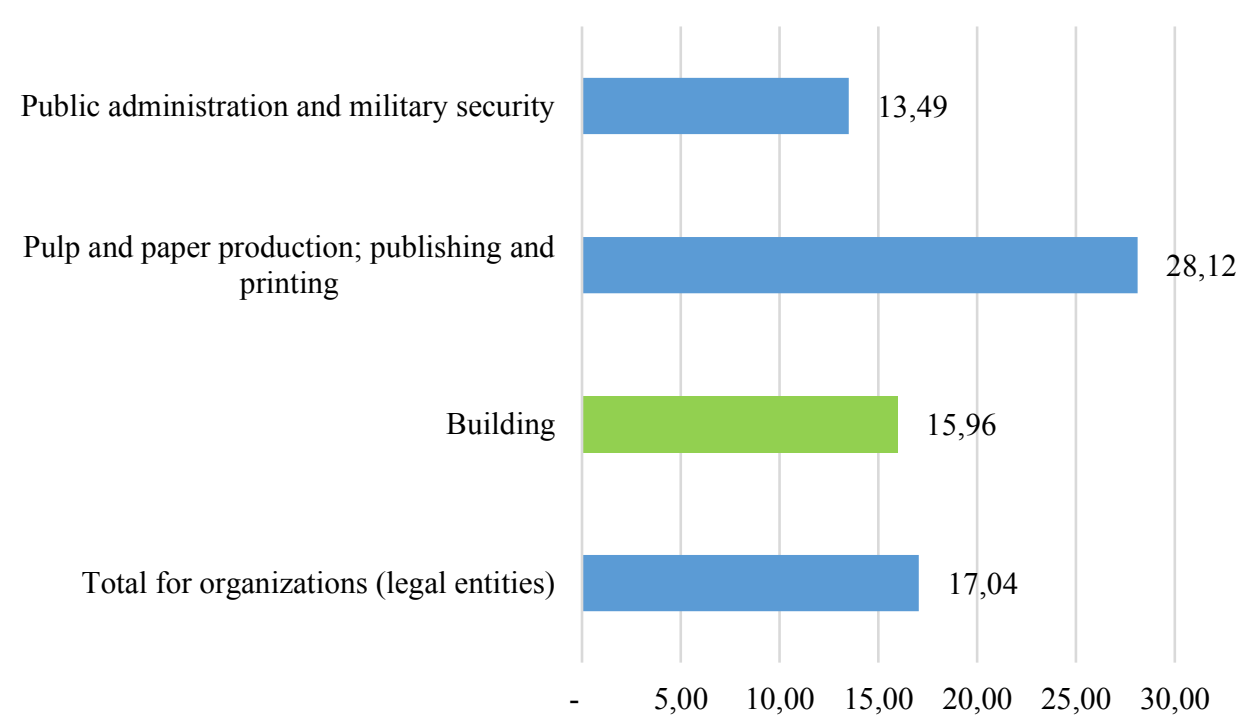

Fig. 1. Comparative analysis of life cycle duration russian subjects of different types of activity.

The seven largest road construction companies in terms of capitalization have an average duration of current operation of 34 years (table 1).

Table 1. Duration of activity of the largest road-building enterprises.

\begin{tabular}{|c|c|}
\hline Road construction subjects & Life cycle, years \\
\hline Mostotrest & 88 \\
\hline Tunnel group № 44 & 25 \\
\hline Ingeocom & 29 \\
\hline USK most & 27 \\
\hline DSK Autobahn & 18 \\
\hline Sibmost & 25 \\
\hline Corporation Inzhtransstroy & 27 \\
\hline The average length & 34 \\
\hline
\end{tabular}

Construction leads in bankruptcy procedures [15] (Fig. 2).

Against the background of the lack of sustainable methods for assessing the socioeconomic environment and the activities of subjects in this environment, we believe it is possible to use the following set of indicators. Summary indicators of the environment: investment capacity, investment attractiveness, market capacity, solvent demand, financial security, tax incentives, business efficiency, regulatory security, institutional efficiency, innovation activity, competition, etc. 


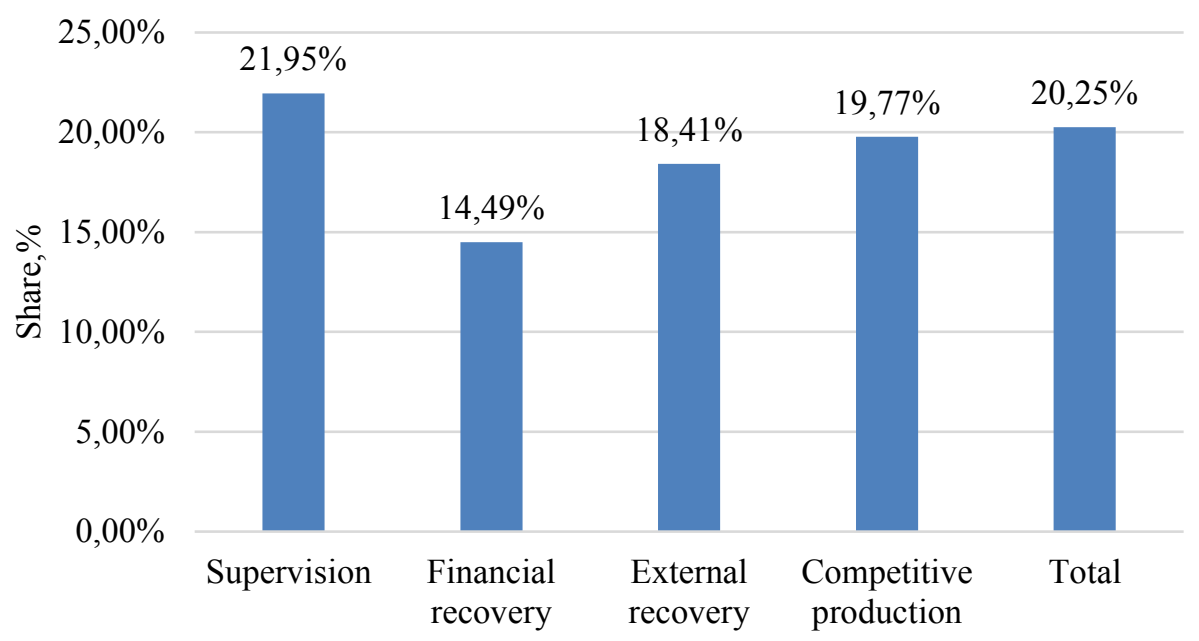

Fig. 2. Share of construction companies in bankruptcy proceedings (2017).

With regard to the activities of subjects in the socio-economic environment can be identified absolute, relative and coefficient indicators. Absolute figures: the number of existing road construction enterprises at the beginning and end of the period, the number of registered enterprises, the number of liquidated enterprises, investment volumes, lending volumes, production volumes, the number of employees. Specific indicators: share in the total number of construction enterprises, contribution to GDP, share of investment and lending, share of employment. Ratio indicators: the density of road construction, the intensity of activities, the updated environment, the rate of occurrence and liquidation of entities, the replacement rate. Coefficient indicators can be estimated point-by-point in statics, in comparison with other types of investment and construction activities, in dynamics. Dynamic studies of indicators of the environment involve the assessment of absolute growth, the growth rate, the absolute content of growth, the rate of increase. Let us consider the basic indicators of the environment of Russian road construction enterprises.

The indicator of density of the environment of activity of the enterprises of road construction $p_{s}$ is defined as follows:

$$
p_{s}=\frac{V_{w}}{N_{s}}
$$

where $V_{w}$-amount of work performed by road construction companies,

$N_{s}$ - number of road construction companies.

According to the database of enterprises of Russia USRLE [16] in 2016 in the market of road construction the number of active enterprises increased by 586 and amounted to 3389 enterprises. In 2017, the number of existing road construction enterprises increased by 267 and amounted to 3665. The volume of work performed on the construction of roads in 2017 amounted to 544.7 billion rubles, which is $19.7 \%$ more than in 2016 . The change in the density of the environment of road construction enterprises is shown in Fig. 3. 


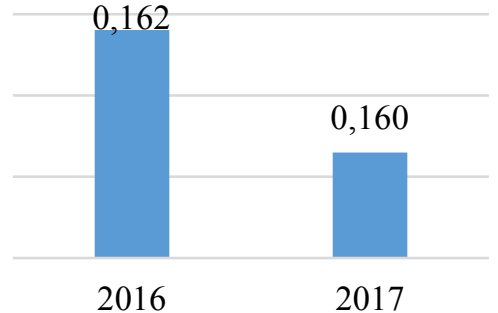

Fig. 3. The dynamics of the medium density activities of Russian enterprises of road construction.

The coefficient of renewal of the environment of activity of the enterprises of road construction $K_{E}$ is determined as follows:

$$
K_{E}=\frac{N_{R}}{N_{B}-N_{L}+N_{R}}
$$

where $N_{B}$ - number of subjects of activity at the beginning of the period,

$N_{R}$ - number of subjects newly registered in the period,

$N_{L}$ - number of entities liquidated in the period.

The coefficient of updatability of the environment can be considered as an integral indicator of other coefficients of structural dynamics of the environment: the coefficient of occurrence of subjects, the coefficient of liquidation of subjects, the replacement coefficient Investment and construction sphere is the leader in the characteristic of updatability $[14,17$, etc.]. Statistical data show that the coefficient of environmental renewability has a significant tendency to increase (Fig. 4).

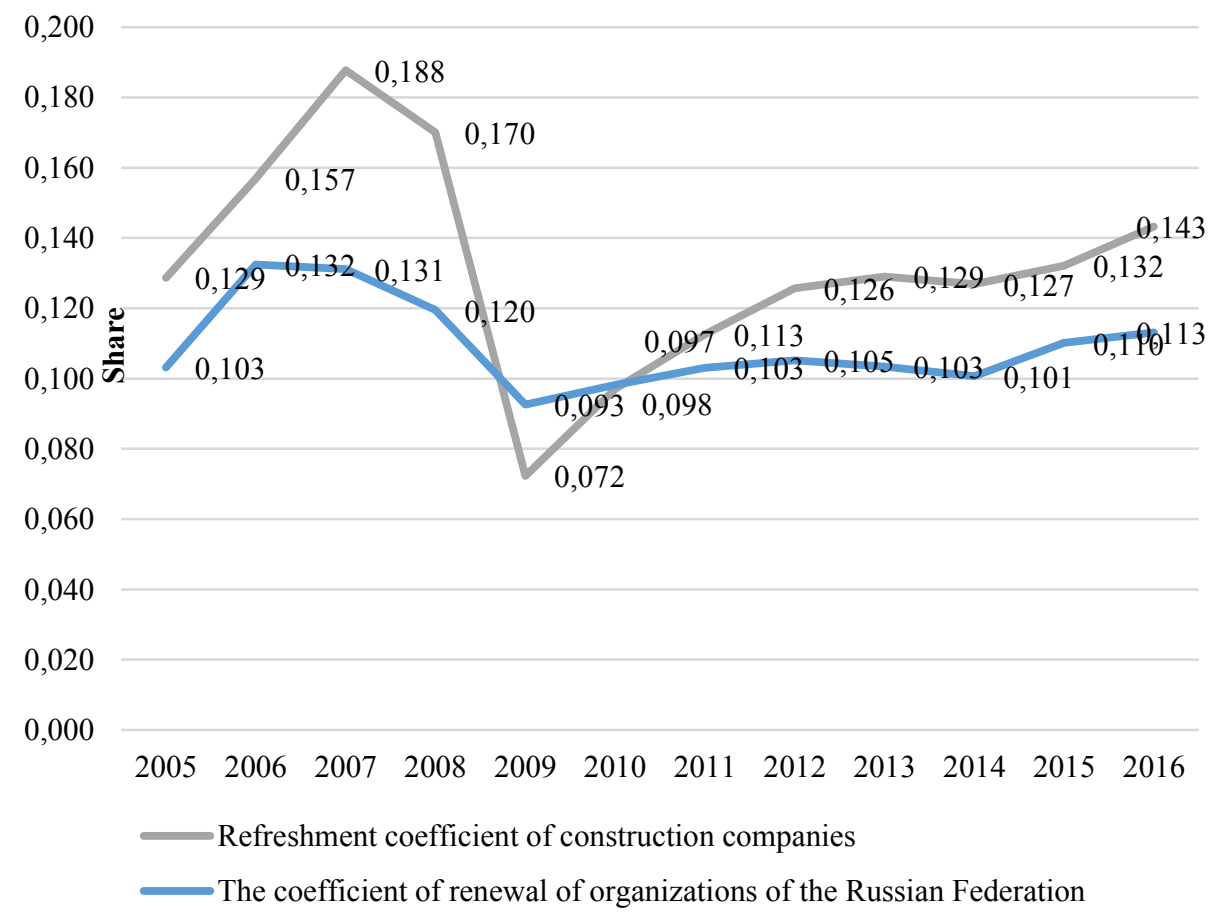

Fig. 4. Comparative analysis of the dynamics of updating the environment of construction companies. 


\section{Discussion}

The decrease in the life cycle of the subjects of enterprisers, the dynamics of density and the coefficient of renewal of the business environment, the change in the number of bankruptcies, the decrease in the capitalization of the largest subjects indicate a high degree of asymmetry of the subject-environment relations in construction. The activity of road construction subjects, as the highest form of activity development, is based on a complex of interrelated internal and external resources, reflects existing and forms future forms of systemic relations $[18$, etc.]. The institutional component of the environment in the form of state regulation plays an important role in these processes of system development (table 2).

Table 2. System of strategic planning of the Russian Federation.

\begin{tabular}{|c|c|c|c|}
\hline Level & Purposefulness & Forecasting & Planning and programming \\
\hline 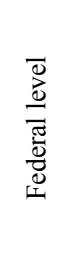 & $\begin{array}{l}\text { Annual Message of the President of } \\
\text { the RF to the Federal Assembly } \\
\text { Strategy of social and economic } \\
\text { development of the RF } \\
\text { National Security Strategy } \\
\text { Strategy of scientific and technical } \\
\text { development of the RF }\end{array}$ & $\begin{array}{l}\text { Budget forecast of the RF for the } \\
\text { long-term period } \\
\text { Forecast of socio-economic } \\
\text { development of the RF for the } \\
\text { long-term and medium-term } \\
\text { period } \\
\text { Strategic forecast of the RF } \\
\text { Forecast of scientific and } \\
\text { technical development of the RF }\end{array}$ & $\begin{array}{c}\text { Main activities of the Government of } \\
\text { the RF } \\
\text { Government programs of the RF } \\
\text { Scheme of territorial planning of the } \\
\text { RF } \\
\text { The State Arms Program } \\
\text { Plans for the activities of federal } \\
\text { executive bodies }\end{array}$ \\
\hline 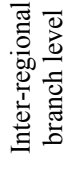 & $\begin{array}{l}\text { Sectoral documents of strategic } \\
\text { planning of the RF } \\
\text { Spatial Planning Strategy of the RF } \\
\text { Strategies of socio-economic } \\
\text { development of macroregions }\end{array}$ & & $\begin{array}{l}\text { Scheme of territorial planning of two } \\
\text { or more subjects of the RF }\end{array}$ \\
\hline \multirow{2}{*}{ 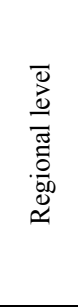 } & \multirow[b]{2}{*}{$\begin{array}{c}\text { Strategies of socio-economic } \\
\text { development of the subject of the } \\
\text { RF }\end{array}$} & \multirow{2}{*}{$\begin{array}{l}\text { Forecast of socio-economic } \\
\text { development of a constituent } \\
\text { entity of the RF for a long-term } \\
\text { period } \\
\text { Budget forecast of the subject of } \\
\text { the RF for the long-term period } \\
\text { Forecast of socio-economic } \\
\text { development of a constituent } \\
\text { entity of the RF for the medium- } \\
\text { term period }\end{array}$} & \\
\hline & & & $\begin{array}{c}\text { Plan of measures to implement the } \\
\text { strategy of social and economic } \\
\text { development } \\
\text { State programs of the subject of the } \\
\text { RF } \\
\text { Scheme of territorial planning of the } \\
\text { subject of the RF }\end{array}$ \\
\hline 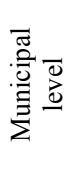 & $\begin{array}{l}\text { Strategy of social and economic } \\
\text { development of the municipality }\end{array}$ & $\begin{array}{l}\text { Forecast of socio-economic } \\
\text { development of the Defense } \\
\text { Ministry for the long-term and } \\
\text { medium-term period } \\
\text { Moscow region budget forecast } \\
\text { for the long-term period }\end{array}$ & $\begin{array}{l}\text { Action plan for the implementation of } \\
\text { the strategy of social and economic } \\
\text { development of the municipality } \\
\text { Municipal programs of the subject of } \\
\text { the RF }\end{array}$ \\
\hline
\end{tabular}

Analysis of the Russian system of strategic planning reveals weaknesses that have development trends in external threats. To a greater extent, this applies to the industry level [19]: the lack of forecasting, copying and duplication of Federal or regional planning processes, violation of consistency, lack of regulatory support, etc. (Figures 5 and 6).

In 2017, a new version of the state program "Development of the transport system of Russia" was prepared. The volume of costs for the implementation of the program in 2017 amounted to 1715.4 billion rubles: at the expense of the Federal budget 658.8 billion rubles (38.4\%), at the expense of the budgets of subjects of the Russian Federation 14.7 billion rubles $(0.9 \%)$, at the expense of extra-budgetary funds 1042 billion rubles (60.7\%). 247.7 billion rubles were allocated for the development of roads, capital expenditures on roads amounted to $24.7 \%$ of the expected volumes [20]. The last numerical value is an indicator of the financial security of the environment of road construction. 


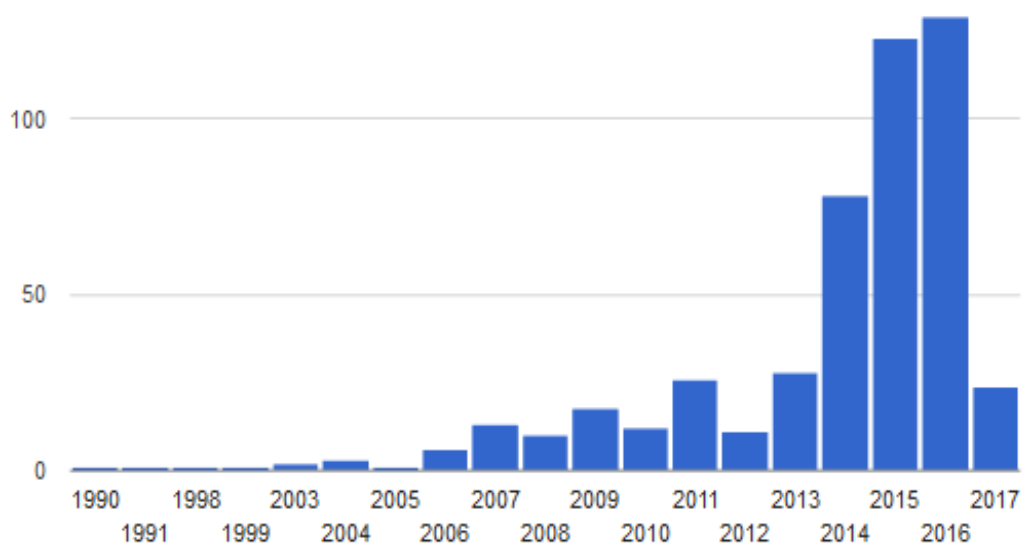

Fig. 5. The dynamics of the regulatory framework for road construction.

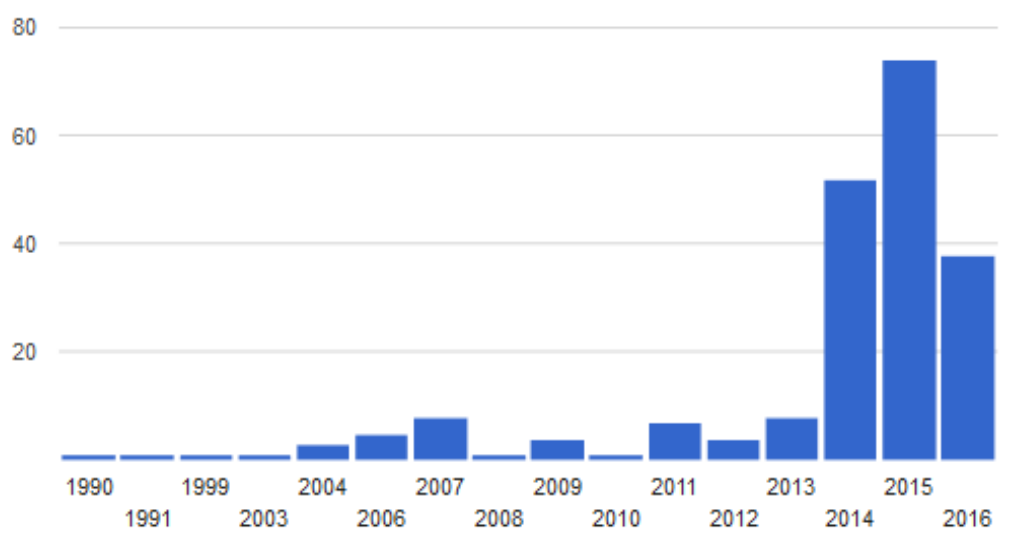

Fig. 6. The dynamics of providing road construction with state Standards.

This decrease in funding led to the exhaustion of previously established technological reserves and a decrease in the volume of commissioning of roads.

Thus, the main factors that had a negative impact on the implementation of measures and achievements of the planned values of the indicators of the Transport strategy (for goal 1 "Formation of a single transport space of Russia on the basis of a balanced advanced development of effective transport infrastructure") are the following indicators of the environment: insufficient volumes of public funding and low investment activity in the transport sector, associated with the high cost of Russian credit resources and the sanctions restriction of access of Russian companies to cheap foreign credit resources.

\section{Conclusion}

The indicators presented in the article indicate the low quality of the environment of the russian road construction enterprises. In further work, we believe to investigate the factors that can have a significant positive impact on the development of the business environment and the creation of conditions for the effective functioning of road construction enterprises: 
- development and testing of methods of integrated assessment of the environment of road construction enterprises in order to manage the environment and improve the performance of Russian road construction enterprises,

- improvement of mechanisms of the state order with strengthening of control, subsidizing by the state of part of design tasks of road construction,

- expansion of mechanisms to attract extra-budgetary sources, development of alternative forms of implementation of road construction projects,

- management of road construction enterprises on an innovative basis - vector regulation of development.

\section{References}

1. R.V. Vasilenko, Methodology, methods, regularities and laws of road construction in the region (on the example of the Leningrad region), monograph (2015)

2. N.In. Kovalenko, V.V. Bujnowska, V.I. Prusova, Car. Road. Infrastructure: electronic scientific journal 1(15) (2018)

3. N.In. Kovalenko, V.V. Bujnowska, E.P. Sukhanova, International journal of Humanities and natural Sciences 11, 148-153 (2017)

4. M.E. Botalova, Bulletin of Belgorod University of cooperation, Economics and law 2, 119-130 (2018)

5. N.N. Kozlenko, V.G. Larionov, Innovations in management 3, 30-38 (2015)

6. P.P. Lutovinov, D.I. Kozlov, Production organizer 26-1, 57-66 (2018)

7. M.Y. Mishlanov, Economics and entrepreneurship 1(54), 745-749 (2015)

8. W. Schmidt, Development Management of an industrial enterprise by economic stability criteria: abstract dis. (2013)

9. F. Wigge. Business Strategy and the Environment/ABI Inform Global, 25-43 (2002)

10. P. Sykes, M. Bell, D. Dissanayake, Transportation Research Part B: Methodological 116, 124-140 (2018)

11. N.In. Knyazev, Y.V. Kalashnikov, Investment and Innovation Management Journal 1, 62-68 (2018)

12. On the prospects of development of the road network in the Russian Federation, Analytical Bulletin 3(556), http://council.gov.ru/media/files/41d53c2113ce 9d34213a.pdf (2015)

13. D.V. Filippov, A.S. Popov, A.A. Kardashevskaya, Transport business in Russia 6, 3-6 (2017)

14. http://www.gks.ru/

15. https://bankrot.fedresurs.ru/

16. https://export-base.ru/okved

17. M.I. Kamenetsky, Forecasting problems 4 (157), 46-57 (2016)

18. Yu.P. Aniskin, Electronic information system 2 (5), 93-102 (2015)

19. http://nto.rosavtodor.ru/analytics.html

20. Report on the implementation of the Transport strategy of the Russian Federation until 2030. Reporting period: 2017, https://www.mintrans.ru/documents/7/9489 (2018) 